\title{
The determinants of exchange rates and the movements of EUR/RON exchange rate via non-linear stochastic processes
}

\author{
Andreea-Cristina PETRICĂ \\ The Bucharest University of Economic Studies, Bucharest, Romania \\ andreea.petrica@yahoo.com \\ Stelian STANCU \\ The Bucharest University of Economic Studies, Bucharest, Romania
}

\begin{abstract}
Modeling exchange rate volatility became an important topic for research debate starting with 1973, when many countries switched to floating exchange rate system. In this paper, we focus on the EUR/RON exchange rate both as an economic measure and present the implied economic links, and also as a financial investment and analyze its movements and fluctuations through two volatility stochastic processes: the Standard Generalized Autoregressive Conditionally Heteroscedastic Model (GARCH) and the Exponential Generalized Autoregressive Conditionally Heteroscedastic Model (EGARCH). The objective of the conditional variance processes is to capture dependency in the return series of the EUR/RON exchange rate. On this account, analyzing exchange rates could be seen as the input for economic decisions regarding Romanian macroeconomics - the exchange rates being influenced by many factors such as: interest rates, inflation, trading relationships with other countries (imports and exports), or investments - portfolio optimization, risk management, asset pricing. Therefore, we talk about political stability and economic performance of a country that represents a link between the two types of inputs mentioned above and influences both the macroeconomics and the investments. Based on time-varying volatility, we examine implied volatility of daily returns of EUR/RON exchange rate using the standard GARCH model and the asymmetric EGARCH model, whose parameters are estimated through the maximum likelihood method and the error terms follow two distributions (Normal and Student's $t$ ). The empirical results show EGARCH $(2,1)$ with Asymmetric order 2 and Student's t error terms distribution performs better than all the estimated standard GARCH models (GARCH(1,1), GARCH(1,2), GARCH(2,1) and GARCH(2,2)). This conclusion is supported by the major advantage of the EGARCH model compared to the GARCH model which consists in allowing good and bad news having different impact on the volatility. The EGARCH model is able to model volatility clustering, persistence, as well as the leverage effect.
\end{abstract}

Keywords: Implied Volatility, Leverage Effect, EGARCH Model, Heteroscedasticity, Fat-tails, Determinants of Exchange Rates, Unit-Root Tests.

\section{Introduction. Literature review}

Talking about a country's economy implies considering many factors that are linked, so they are positive or negatively correlated, and give an overview of the country's health. Currency movements represent a natural outcome of the floating exchange rate system developed after quitting the Bretton Woods system based on 2 principles that incorporated the fixed exchange rate gold standard and the floating rates which means the independence to continue to explore national full employment policies.

In our previous work we have pointed out that "volatility represents an important tool in Economy and plays an important role in the area of risk management" (Petrică and Stancu, 2017, p. 58), fact that will also be highlighted hereinafter. Therefore, in this paper we focus on the exchange rate both as an economic measure and present the implied 
economic links, but also as an investment by analyzing the changes in volatility through two volatility stochastic processes: the Standard Generalized Autoregressive Conditionally Heteroscedastic Model (GARCH) and the Exponential Generalized Autoregressive Conditionally Heteroscedastic Model (EGARCH), whose objective is to capture dependency in the return series.

\section{Determinants of exchange rates}

Many elements determine exchange rates, and all are linked to each other. It is worth mentioning that exchange rates are expressed in terms of the currency of another country. Thus, the exchange rate shows how much of the second currency is needed (in our case RON) to purchase that one unit of the first currency (EUR). From the factors that decisively affects the nature of exchange rates (the major forces behind exchange rate movements) we recall the following:

a) Inflation and interest rates - these two elements are much related and have a big influence on the exchange rate. The relationship between inflation and interest rates is complex and not easy to analyze. Suppose that European Central Bank reduces the interest rate. This leads to lower interest rates on loans, increasing the number of loans and the consumption of goods and services in that country. At the same time, the granting of money at a lower price will lead to devaluation of the national currency relative to other currencies, so it causes increasing inflation rates. Generally, low interest rates tend to have a positive influence on currency, but they do not attract foreign investment. We have shown that a change in interest rates influence both inflation and exchange rates, meaning there is a high correlation between the three forces discussed above.

b) Current account and terms of trade - The current account represents the balance of trade between a country and its trading partners and reflects all payments between them for goods, services, interest and so on. A deficit in the current account implies spending more on foreign trade than it is earning, which leads to having a deficit. Regarding the terms of trade, an increase shows greater demand for the country's exports, which implies higher earnings from exports and higher demand for the country's currency. Hence, it results the relationship with current accounts.

c) Public debt - this is the case of public sector projects and governmental funding. Doing so, it stimulates the domestic economy, but on the other hand a country having large public deficits and debts is not attractive to foreign investors because inflation is encouraged.

d) Political stability and economic performance are vital features tracked by investors and the explication is simple - a stable country and having a strong economy leads to a less risky investment. Contrariwise, if we are dealing with a high political risk then it causes a loss of confidence in that currency.

In the following, for a summary of the recent literature we mention the following studies:

Suska (2015) points out that from the very beginning of exchange trading, both economists and econometricians have been interested in modeling and forecasting financial instruments. The series of share prices of the fifty largest and most liquid companies listed on the Warsaw Stock Exchange have been analyzed using six GARCH models: the standard GARCH, EGARCH, GJR-GARCH, AP(G)ARCH, FIEGARCH and FIAPGARCH. The conclusion 
derived from the analysis performed is that the leverage effect constitutes an important part in modeling the conditional variance of a time series and that 48 companies out of 50 show the presence of the asymmetry, a phenomenon which improves the quality of the volatility model.

The empirical usefulness of leverage effect is also explored by Chorro et al. (2014) in order to give details of the dynamics of asset returns. To do this, they employ two classical asymmetric GARCH models (EGARCH and Power ARCH) with two families of conditional distributions that are able to generate various levels of skewness and kurtosis the Generalized Hyperbolic distribution and the mixture of two Gaussian distributions) in order to disentangle the part of the skewness effectively coming from the leverage effect and the part coming from the left tail of the conditional distribution. The analysis outcome consists in a weak contribution of leverage effect over the past 25 years of S\&P 500 returns.

The analysis performed by Abdalla and Winker (2012) is based on stock market volatility in two African exchanges (Khartoum Stock Exchange and Alexandria Stock Exchange). The asymmetrical GARCH estimation (EGARCH(1,1) and TGARCH(1,1)) displays a significant evidence for asymmetry in both analyzed stock returns, confirming the presence of leverage effect in return series.

Furthermore, Abdalla (2012) implements the GARCH(1,1) and EGARCH(1,1) models in analyzing the exchange rate volatility in nineteen Arab countries against the US dollar. Once more time, the asymmetrical EGARCH $(1,1)$ results find evidence for leverage effects for 18 exchange rates out of 19 .

\section{Methodology}

Next, the two volatility models and the distributions of the error terms $e_{t}$ are presented and discussed. Firstly, we give the basic structure of a GARCH model which consists in "two equations, one for conditional mean (the predictable component) - where the Box-Jenkins approach can be used, and another one for conditional variance which represents the unpredictable component - where the innovation terms from the conditional mean are modeled" (Petrică and Stancu, 2017, p. 59), $\left\{Z_{t}\right\}$. The general representation for the conditional mean and conditional variance are as follows:

And

$$
\mu_{t}=E\left(R_{t} \mid I_{t-1}\right)
$$

$$
h_{t}^{2}=\operatorname{Var}\left(R_{t} \mid I_{t-1}\right) \stackrel{\text { def }}{=} E\left[\left(R_{t}-\mu_{t}\right)^{2} \mid I_{t-1}\right]=E\left(Z_{t}^{2} \mid I_{t-1}\right)
$$

Where:

$\mu_{t}$ - conditional mean;

$h_{t}^{2}$ - conditional variance;

$R_{t}$ - daily log return;

$E(. \mid$.$) - conditional expectation;$

$I_{t-1}$ - information available at time $t-1$;

$Z_{t}:=R_{t}-\mu_{t}$.

This paper focuses on conditional variance, which will be described in the special stochastic processes used to provide a way to model conditional heteroscedasticity in volatility of EUR/RON exchange rate. 


\section{Normal (Gaussian) distribution}

The normal distribution is the most common and used continuous probability distribution, whose importance derive from the central limit theorem.

Let $\left\{e_{t}\right\}$ be the sequence of error terms, which are independent, identically distributed having $E\left(e_{t}\right)=0$ and $\operatorname{Var}\left(e_{t}\right)=1$.

To give a complete specification of a $\operatorname{GARCH}(p, q)$ model it is necessary to determine the parameters $p$ and $q$ (i.e. the order of the process) and to assume a distribution for the error terms (EViews 9.5 provides five types of distributions).

We say that a random variable $X$ is normally distributed $\left(X \sim N\left(\mu, \sigma^{2}\right)\right)$ if the density function is defined as:

$$
f(x)=\frac{1}{\sqrt{2 \pi} \sigma} e^{-\frac{(x-\mu)^{2}}{2 \sigma^{2}}},-\infty<x<\infty
$$

It is known that financial series presents fat-tails. This property implies an additional risk and makes them to be unwanted, fact that leads to alternative distribution assumptions for the error terms such as Student's t. On the other hand, lots of studies regarding GARCH modeling proved that Student's $t$ or the generalized error distributions performs better than the normal distribution.

\section{Student-t distribution}

Student-t distribution is also a continuous probability distribution, but the difference between Student-t distribution and Normal distribution is that the first one assumes $\sigma$ unknown and approximates it with $s$ (fact that leads to more variability than $\sigma$.)such that the distribution can be expressed in the following way:

$$
t=\frac{\bar{x}-\mu}{s \sqrt{n}}
$$

Where $n$ represents the number of observations and the population from which the sample was substract is normally distributed.

The density function of a Student-t distribution with $v$ degrees of freedom $(v>0)$ is defined as:

$$
f(x)=\frac{\Gamma\left(\frac{v+1}{2}\right)}{\sqrt{v \pi} \Gamma\left(\frac{v}{2}\right)}\left(1+\frac{x^{2}}{v}\right)^{-\left(\frac{v+1}{2}\right)},-\infty<x<\infty
$$

Having:

$\mu=0$ for $v \geq 2$;

$\sigma^{2}=\frac{v}{v-2}$ for $v \geq 3$

$\gamma_{2}=\frac{6}{v-4}$ for $v \geq 5, \gamma_{2}$ represents the coefficient of kurtosis;

$\Gamma$ represents the gamma function $\left(\Gamma(x)=\int_{0}^{\infty} y^{x-1} e^{-y} d y\right.$.).

The reason for which Student's t distribution is preferred instead of Normal distribution is because the last one cannot sufficiently take into consideration fat-tails in modeling financial time series using GARCH or EGARCH models. 
Going further to autoregressive conditionally heteroscedastic models, the main difference between the standard GARCH and EGARCH models consists in the impact of positive and negative news on volatility, the first model couldn't explain the leverage effect (Leverage effect means that negative news affect more the volatility than the positive news.).

\section{The Generalized Autoregressive Conditionally Heteroscedastic Model (GARCH)}

The GARCH model introduced by Bollerslev in 1986 as a generalization of the ARCH model is able to model the volatility clustering, a characteristic of financial time series, but does not model the leverage effect (i.e. the asymmetric effect of positive and negative returns). Thus, the $\operatorname{GARCH}(p, q)$ model for the time series $Z_{t}$ (residual returns) is given by:

$$
Z_{t}=h_{t} e_{t}
$$

Where $\left\{e_{t}\right\}$ are standardized residual returns i.e. independent, identically distributed random variables with $E\left(e_{t}\right)=0$ and $\operatorname{Var}\left(e_{t}\right)=1$.

$$
h_{t}^{2}=\alpha_{0}+\sum_{i=1}^{p} \alpha_{i} Z_{t-i}^{2}+\sum_{j=1}^{q} \beta_{j} h_{t-j}^{2}
$$

Where:

$\alpha_{i} \equiv 0$, for $i>p$;

$\beta_{j} \equiv 0$, for $j>q$.

Now the purpose is to have a conditional variance equation that is well defined and a stationary $h_{t}^{2}$, so the following restrictions are required:

$\alpha_{0}>0, \alpha_{i} \geq 0, \beta_{j} \geq 0$ and $\sum_{i=1}^{q} \alpha_{i}+\sum_{j=1}^{p} \beta_{j}<1$.

Rewriting the conditional variance equation in terms of the lag operator $L$ (backward shift operator) as presented in (Petrică and Stancu, 2017, p. 61), we get:

$$
\sigma_{t}^{2}=\omega+\left(\sum_{i=1}^{q} \alpha_{i} L^{i}\right) \varepsilon_{t}^{2}+\left(\sum_{j=1}^{p} \beta_{j} L^{j}\right) \sigma_{t}^{2}
$$

Where:

$\omega$ - constant term;

$\alpha_{i}-\mathrm{ARCH}$ terms i.e. volatility shocks from prior periods.

$\beta_{j}-$ GARCH terms i.e. the persistence of volatility.

In other words, the GARCH model express conditional variance at time $t$ as "a linear function of past squared errors and past conditional variances. Difference from the ARCH model is that GARCH model allows the conditional variance to be modeled by past values of itself in addition to the past shocks" (Rachev et al., 2007, p. 284).

The standard GARCH model investigates the volatility clustering and persistence, but it does not capture the leverage effect. The reason why is happening this is because the standard GARCH model treats the conditional variances only depending on the magnitudes of the past values and is not considering the signs of the shocks. 


\section{The Exponential Generalized Autoregressive Conditionally Heteroscedastic Model (EGARCH)}

EGARCH represents an asymmetric GARCH model that was introduced by (Nelson, 1991) and has two advantages over the standard GARCH model: it models leverage effect and ensures always a positive variance so there is no need for imposing constraints.

The $\operatorname{EGARCH}(p, q)$ model for the residual returns $Z_{t}=h_{t} e_{t}, e_{t} \sim I I D(0,1)$ is given by:

$$
\log \left(h_{t}^{2}\right)=\alpha_{0}+\sum_{i=1}^{p}\left[\alpha_{i} Z_{i}+\gamma_{i}\left(\left|Z_{t-i}\right|-E\left(\left|Z_{t-i}\right|\right)\right)\right]+\sum_{j=1}^{q} \beta_{j} \log \left(h_{t-j}^{2}\right)
$$

PICBE | 942

Next, we provide how the asymmetrical effects of positive and negative asset returns works by making use of the EGARCH $(1,1)$ model and a function $g$ of the residual returns defined through $g\left(Z_{t}\right)=\left(\alpha_{1}+\gamma_{1}\right) Z_{t} I\left(Z_{t}>0\right)+\left(\alpha_{1}-\gamma_{1}\right) Z_{t} I\left(Z_{t}<0\right)-\gamma_{1} E\left(\left|Z_{t}\right|\right)$. Thus, if we consider the impact on the logarithm of the conditional variance as being $\operatorname{Imp}$, then we get Imp $=\left\{\begin{array}{l}\alpha_{1}+\gamma_{1}, \text { positive shocks } \\ \alpha_{1}-\gamma_{1}, \text { negative shocks }\end{array}\right.$.

Assuming other factors remaining unchanged, negative returns shocks generate more volatility than the positive ones. The EGARCH model is characterized precisely by capturing the asymmetric responses (leverage effect) of the conditional variance to shocks.

\section{Data and empirical results}

Generally, when we talk about EUR/RON exchange rate volatility we mean it as a measure of the movements and fluctuations in the exchange rates evolution or as a risk measurement, which underlies economic decisions.

The EUR/RON exchange rate series is retrieved from the National Bank of Romania and takes into account the period 01/04/1999 - 06/13/2016 (4439 daily observations). In this section, based on time-varying volatility, we examine implied volatility of daily returns of EUR/RON exchange rate using the standard GARCH model and the asymmetric EGARCH model, estimated using the maximum likelihood method under the assumption and two distributions of the error terms $e_{t}$ (Normal and Student's t-distributions). It is worth mentioning the difference between the two types of volatility: historical and implied. The first one is good if there is no structural changes in the economy and thus the standard deviation and the annual volatility of the exchange rate can be easily computed from the past values of the analyzed exchange rate. Contrariwise, the implied volatility is more complex and it is seen as "a forward looking measure of volatility and is calculated from the market participants estimates of what is likely to happen in the future" (Abdalla, 2012, p. 217). Thus, it is estimated based on the quoted price of a currency option having all other parameters known.

The variable to be modelled is percentage daily EUR/RON exchange rate return, as the new time series is stationary, computed as the first difference of the natural logarithm:

Where:

$$
R_{t}=100 * \log \left(\frac{p_{t}}{p_{t-1}}\right)
$$

$R_{t}$ - the return of daily EUR/RON exchange rate;

$p_{t}$ - the EUR/RON exchange rate at time $t$, considered the current day;

$p_{t}$ - the EUR/RON exchange rate at time $t-1$, so the value from the previous day. 
The graphical representation of EUR/RON exchange rate (Figure 1) indicates some trends and gives an intuitive grasp of the non-stationarity.

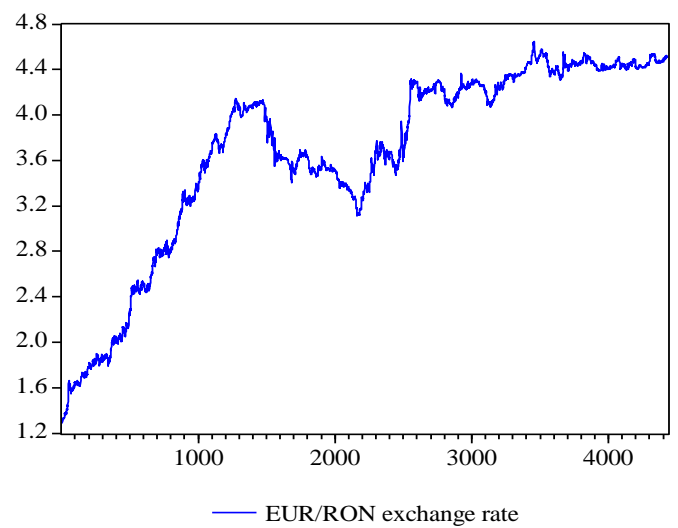

PICBE | 943

Figure 1. The evolution of the EUR/RON exchange rate

Source: Authors' own research.

For a more appropriate interpretation, we investigate stationarity through some statistical tools represented by the unit-root tests (Table 1):

Table 1. The unit-root tests with intercept and trend applied to EUR/RON exchange rate series

\begin{tabular}{|c|c|c|c|c|}
\hline \multirow{2}{*}{\multicolumn{2}{|c|}{$\begin{array}{l}\text { Unit-root Test } \\
\text { (Prob.) }\end{array}$}} & \multicolumn{3}{|c|}{ Critical Values } \\
\hline & & $1 \%$ & $5 \%$ & $10 \%$ \\
\hline Augmented Dickey-Fuller & $\begin{array}{c}-2.377248 \\
(0.3915)\end{array}$ & -3.960107 & -3.410818 & -3.127206 \\
\hline Phillips-Perron & $\begin{array}{c}-2.371825 \\
(0.3944)\end{array}$ & -3.960106 & -3.410817 & -3.127205 \\
\hline
\end{tabular}

Source: Authors' own research.

The results of the two unit-root tests validate the graphical interpretation of daily EUR/RON exchange rate series, thus it is not stationary. This fact comes as no surprise as financial time series are characterized by non-stationarity.

In contrast to the raw series, the new series of returns is stationary at all conventional confidence levels: $1 \%, 5 \%$ and $10 \%$ (see Figure 2 and Table 2):

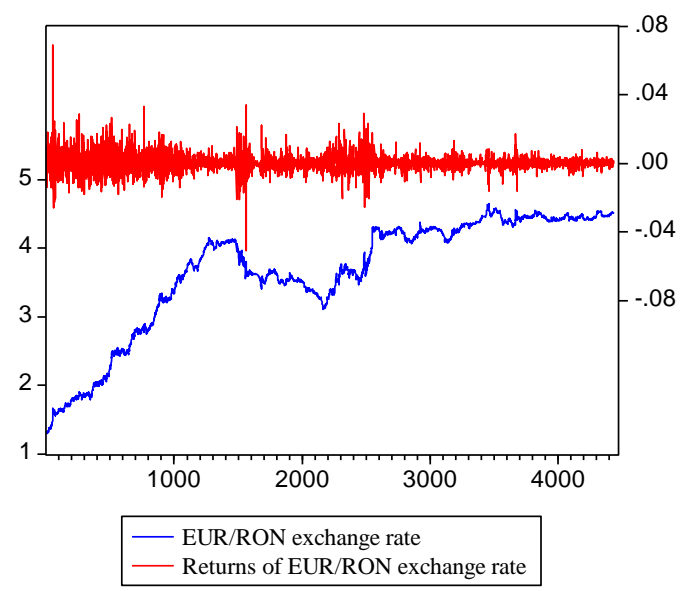

Figure 2. The evolution of daily returns for the EUR/RON exchange rate comparative to the evolution of the raw series

Source: Authors' own research. 
Table 2. The unit-root tests with intercept and trend applied to returns

\begin{tabular}{|c|c|c|c|c|}
\hline \multicolumn{2}{|c|}{$\begin{array}{c}\text { Unit-root Test } \\
\text { (Prob.) }\end{array}$} & $\mathbf{1 \%}$ & $\mathbf{5 \%}$ & $\mathbf{1 0 \%}$ \\
\cline { 3 - 5 } & -41.39923 & -2.565484 & -1.940895 & -1.616652 \\
\hline Augmented Dickey-Fuller & $(0.0000)$ & & & -1.616652 \\
\hline Phillips-Perron & -59.48531 & -2.565483 & -1.940895 & \\
\hline
\end{tabular}

Source: Authors' own research.

Table 3. Descriptive Statistics of daily returns for the EUR/RON exchange rate

\begin{tabular}{|l|c|}
\hline Indicators & Daily EUR/RON returns \\
\hline Skewness & 0.884889 \\
Kurtosis & 17.01422 \\
Jarque-Bera & 36896.51 \\
(Probability) & $(0.000000)$ \\
\hline
\end{tabular}

Source: Authors' own research.

The most important descriptive statistics are presented in Table 3. Positive Skewness is the evidence of asymmetry in the series and a Kurtosis coefficient grater than 3 suggests a leptokurtic distribution. In a normally distributed series the coeficients' values are zero for Skewness and 3 for Kurtosis. Non-normality is also highlighted through JarqueBera test, who's value is 36896.51 with probability zero.

Even if the central point in the paper is modeling the implied volatility, for working properly the conditional variance model implies estimating also the conditional mean. We assume that conditional mean follows a stationary mixed autoregressive moving average process $\operatorname{ARMA}(r, s)$. Thus, we have the following equations:

And

$$
R_{t}=\mu_{t}+Z_{t}
$$

$$
\mu_{t}=\varphi_{0}+\sum_{k=1}^{r} \varphi_{k} R_{t-k}-\sum_{l=1}^{s} \theta_{l} Z_{t-l}
$$

After employing the Box-Jenkins methodology we find that the adequate model for modeling the conditional mean is a simple autoregressive model of order 3 (i.e. AR(3)) and the output is presented in Table 4.

Table 4. EViews 9.5 output for the conditional mean equation

\begin{tabular}{crccc}
\hline \hline \multicolumn{1}{c}{ Variable } & Coefficient & Std. Error & t-Statistic & Prob. \\
\hline \hline C & 0.027958 & 0.007698 & 3.631662 & 0.0003 \\
AR(1) & 0.107783 & 0.009137 & 11.79566 & 0.0000 \\
AR(2) & -0.073076 & 0.008857 & -8.250409 & 0.0000 \\
AR(3) & -0.063308 & 0.010010 & -6.324349 & 0.0000 \\
SIGMASQ & 0.252541 & 0.002135 & 118.2723 & 0.0000 \\
\hline \hline & & & \\
R-squared & 0.021233 & Mean dependent var & 0.027961 \\
Adjusted R-squared & 0.020350 & S.D. dependent var & 0.508013 \\
S.E. of regression & 0.502818 & Akaike info criterion & 1.463956 \\
Sum squared resid & 1120.776 & Schwarz criterion & 1.471164 \\
Log likelihood & -3243.519 & Hannan-Quinn criter. & 1.466498 \\
F-statistic & 24.04200 & Durbin-Watson stat & 1.998650 \\
Prob(F-statistic) & 0.000000 & & &
\end{tabular}




\begin{tabular}{llll}
\hline \hline Inverted AR Roots & $.21-.40 \mathrm{i}$ & $.21+.40 \mathrm{i}$ & -.31 \\
\hline \hline
\end{tabular}

Source: Authors' own research.

So, the conditional mean has the following equation:

$$
R_{t}=0.000280+0.108055 R_{t-1}-0.072996 R_{t-2}-0.063296 R_{t-3}+Z_{t}
$$

Going further to autoregressive conditionally heteroscedastic models, we retrieve the error terms $\left\{Z_{t}\right\}$ from the AR(3) conditional mean and test them for ARCH effects in order to set up if the conditional variance is time-varying or not. The null hypothesis of ARCH-LM test "There are no ARCH effects in the residual series" is rejected (Obs $* R-$ squared $=88.14303$ with zero probability), so we can estimate the conditional variance for daily returns of EUR/RON exchange rate using the GARCH and EGARCH models.

Thus, we proceed to examine implied volatility of daily returns of EUR/RON exchange rate using the standard GARCH model and the asymmetric EGARCH model, whose parameters are estimated through the maximum likelihood method and the error terms follow two distributions (Normal and Student's t). The empirical results (significant coefficients and minimum Akaike Information Criterion) show that EGARCH(2,1) with Asymmetric order 2 and Student's t error terms distribution performs better than all the estimated standard GARCH models (GARCH(1,1), GARCH(1,2), GARCH(2,1) and GARCH(2,2)). Table 5 presents the values of Akaike Information Criterion for each model and error terms distribution, while Table 6 indicates the conditional variance equation for daily returns of EUR/RON exchange rate:

Table 5. Akaike Information Criterion for standard GARCH and EGARCH models

\begin{tabular}{|l|c|c|}
\hline \multirow{2}{*}{ Estimated Model } & \multicolumn{2}{|c|}{ Error Distribution } \\
\cline { 2 - 3 } & Normal Distribution & Student's t Distribution \\
\hline GARCH$(1,1)$ & $0.882523^{*}$ & 0.797746 \\
\hline GARCH(1,2) & $0.876557^{* *}$ & 0.795905 \\
\hline GARCH(2,1) & $0.876426^{* * *}$ & 0.795377 \\
\hline GARCH(2,2) & $0.876780^{* * *}$ & $0.795822^{*}$ \\
\hline EGARCH(1,1) Asymmetric order 1 & 0.884665 & $0.794197 * *$ \\
\hline EGARCH(1,1) Asymmetric order 2 & 0.881407 & 0.791276 \\
\hline EGARCH(1,2) Asymmetric order 2 & 0.875815 & $0.789429 * * *$ \\
\hline EGARCH(2,1) Asymmetric order 2 & 0.875409 & 0.787957 \\
\hline
\end{tabular}

Source: Authors' own research.

Where:
\begin{tabular}{|c|l|l|l|}
\hline Notes & Coefficient(s) & $\begin{array}{l}\text { Statistically } \\
\text { significant at 10\% } \\
\text { confidence level }\end{array}$ & $\begin{array}{l}\text { Insignificant at any } \\
\text { confidence level }\end{array}$ \\
\hline$*$ & AR(2) & & \\
\hline$* *$ & AR(3) & & \\
\hline$* * *$ & AR(2) and AR(3) & & \\
\hline $\bar{*}$ & GARCH(-2) & & \\
\hline$\overline{* *}$ & RESID(-1)/@SQRT(GARCH(-1)) & & \\
\hline$* * *$ & RESID(-1)/@SQRT(GARCH(-1)) & \\
\hline
\end{tabular}


Table 6. EViews 9.5 output for conditional variance equation represented by EGARCH(2,1) Asymmetric order 2 - Student's t error distribution

\begin{tabular}{crccc}
\hline \hline \multicolumn{1}{c}{ Variable } & Coefficient & Std. Error & z-Statistic & Prob. \\
\hline \hline AR(1) & 0.047834 & 0.016246 & 2.944421 & 0.0032 \\
AR(2) & -0.036291 & 0.014342 & -2.530440 & 0.0114 \\
AR(3) & -0.041527 & 0.014480 & -2.867885 & 0.0041 \\
\hline \hline \multicolumn{5}{c}{ Variance Equation } \\
\hline C(5) & -0.193853 & 0.015252 & -12.71001 & 0.0000 \\
C(6) & 0.416476 & 0.043840 & 9.499823 & 0.0000 \\
C(7) & -0.167695 & 0.042571 & -3.939215 & 0.0001 \\
C(8) & 0.059061 & 0.029140 & 2.026764 & 0.0427 \\
C(9) & -0.078136 & 0.028240 & -2.766824 & 0.0057 \\
C(10) & 0.993305 & 0.002386 & 416.3580 & 0.0000 \\
\hline \hline T-DIST. DOF & 4.675421 & 0.350120 & 13.35377 & 0.0000 \\
\hline \hline R-squared & 0.013024 & Mean dependent var & 0.028004 \\
Adjusted R-squared & 0.012355 & S.D. dependent var & 0.507977 \\
S.E. of regression & 0.504829 & Akaike info criterion & 0.787957 \\
Sum squared resid & 1129.250 & Schwarz criterion & 0.803824 \\
Log likelihood & -1736.294 & Hannan-Quinn criter. & 0.793552 \\
Durbin-Watson stat & 1.873648 & & & \\
\hline \hline Inverted AR Roots & $.17+.33 i$ & .17-.33i & -.30 \\
\hline \hline
\end{tabular}

Source: Authors' own research

The EGARCH(2,1) results presented in Table 6 reveal that all the estimated coefficients are statistically significant at the 1\% confidence level. According to ARCH-LM Test we cannot reject the null hypothesis, so there is no ARCH effect left (Obs. ${ }^{*}$ R-squared= 0.238921 with Prob. Chi-Square(1)=0.6250).

Therefore, the conditional variance has the following equation:

$$
\begin{aligned}
& \log \left(\sigma_{t}^{2}\right)=-0.193853+0.416476 \cdot \frac{\left|\varepsilon_{t-1}\right|}{\sigma_{t-1}}-0.167695 \cdot \frac{\left|\varepsilon_{t-2}\right|}{\sigma_{t-2}}+ \\
& \quad+0.059061 \cdot \frac{\varepsilon_{t-1}}{\sigma_{t-1}}-0.078136 \cdot \frac{\varepsilon_{t-2}}{\sigma_{t-2}}+0.993305 \cdot \log \left(\sigma_{t-1}^{2}\right)
\end{aligned}
$$

From the conditional variance equation we can see the following:

(i) The negative correlation between EUR/RON exchange rate's volatility and exchange rate's returns is suggested by the asymmetry coefficients $\gamma_{1}=0.059061$ and $\gamma_{2}=-0.078136$ (indicates that negative shocks imply a higher next period volatility than positive shocks of the same sigh, which indicates the existence of leverage effects in the daily returns of EUR/RON exchange rate ).

(ii) The GARCH coefficient (0.993305) indicates a slowly decreasing of the rises in the conditional variance due to shocks. 


\section{Conclusions}

Modeling exchange rate volatility became an important topic for research debate starting with 1973, when many countries switched to floating exchange rate system. In this paper, we focus on the EUR/RON exchange rate both as an economic measure and a financial investment. We analyze its movements and fluctuations through two volatility stochastic processes: the Standard GARCH and the Exponential GARCH. The objective of the conditional variance processes is to capture dependency in the return series of the EUR/RON exchange rate. On this account, analyzing exchange rates could be seen as the input for economic decisions regarding Romanian macroeconomics - the exchange rates being influenced by many factors such as: interest rates, inflation, trading relationships with other countries (imports and exports), or investments - portfolio optimization, risk management, asset pricing. Based on time-varying volatility, we examine implied volatility of daily returns of EUR/RON exchange rate using the standard GARCH model and the asymmetric EGARCH model, whose parameters are estimated through the maximum likelihood method and the error terms follow two distributions (Normal and Student's $\mathrm{t}$ ). The empirical results show EGARCH(2,1) with Asymmetric order 2 and Student's t error terms distribution performs better than all the estimated standard GARCH models (GARCH(1,1), GARCH(1,2), GARCH(2,1) and GARCH(2,2)). The first one who concentrated on the leverage effect was (Black, 1976). The leverage effect, also known as the asymmetric effect, represents the negative correlation between past returns (in our case EUR/RON exchange rate returns) and its future volatility, which means that the variance of returns increases with a decrease in prices. The $\operatorname{EGARCH}(2,1)$ estimated coefficients are statistically significant at the 1\% confidence level and according to ARCH-LM Test the null hypothesis can not be rejected, so there is no ARCH effect left and the conditional variance equation is well specified. This conclusion is supported by the major advantage of the EGARCH model compared to the GARCH model which consists in allowing good and bad news having different impact on the volatility. The EGARCH model is able to model volatility clustering, persistence, as well as the leverage effect. Having these results in mind, it is left to future research to study the theoretical and mathematical representations of the relationships between exchange rates, inflation, interest rates, imports and exports.

\section{References}

Abdalla, S.Z. (2012). Modelling Exchange Rate Volatility using GARCH Models: Empirical Evidence from Arab Countries, International Journal of Economics and Finance, 4(3), 216-229.

Abdalla, S.Z. and Winker, P. (2012). Modelling Stock Market Volatility using Univariate GARCH Models: Evidence from Sudan and Egypt, International Journal of Economics and Finance, 4(8), 161-176.

Akaike, H. (1976). Canonical Correlation Analysis of Time Series and The Use of An Information Criterion, Academic Press.

Black, F. (1976). Studies of stock prices volatility changes, Proceedings of the 1976 Meetings of the American Statistical Association, Business and Economics Statistics Section, 177189. 
Bollerslev, T. (1986). Generalized Autoregressive Conditional Heteroskedasticity, Journal of Econometrics, 31, 307-327.

Christoffersen, P.F. (2012). Elements of Financial Risk Management (2 ${ }^{\text {nd }}$ Ed.), Academic Press.

Chorro, C., Guegan, D., Ielpo, F., Lalaharison, H. (2014). Testing for Leverage Effect in Financial Returns. Documents de travail du Centre d'Economie de la Sorbonne 2014.22, ISSN: 1955-611X. Retrieved from: https://hal.inria.fr/file/index/docid/973922/filename/14022.pdf.

Dickey, D.A. and Fuller, W.F. (1979). Distribution of the Estimators for Autoregressive Time Series with a Unit Root, Journal of the American Statistical Association, 74(366), 427431.

Engle, R.F. (1982). Autoregressive Conditional Heteroscedasticity with Estimates of the Variance of United Kingdom Inflation, Econometrica, 50(4), 987-1008.

Nelson, D.B. (1991). Conditional Heteroskedasticity in Asset Returns: A New Approach, Econometrica, 59(2), 347-370.

Petrică, A.C. and Stancu, S. (2017). Empirical Results of Modeling EUR/RON Exchange Rate using ARCH, GARCH, EGARCH, TARCH and PARCH Models, Romanian Statistical Review, 1, 57-72.

Phillips, P.C. . and Perron, P. (1988). Testing for a unit root in time series regression, Biometrika, 75(2), 335-346.

Rachev, S.T., Mittnik, S., Fabozzi, F.J., Focardi, S.M. and Jasic, T. (2007). Financial Econometrics: From Basics to Advanced Modeling Techniques, John Wiley \& Sons, Inc., New Jersey.

Suska, J. (2015). Modelling Leverage Effect in a Financial Time Series, Finance, Financial Markets, Insurance, 73(854), 843-852. Retrieved from www.wneiz.pl/frfu.

Tsay, R.S. (2013). An Introduction to Analysis of Financial Data with R, John Wiley \& Sons, Inc., Hoboken, New Jersey. 